\title{
Iatrogenic Aortocoronary Arteriovenous Fistula following Coronary Artery Bypass Surgery: A Case Report and Complete Review of the Literature
}

\author{
Jonathan D. Gardner, ${ }^{1}$ William R. Maddox, ${ }^{2}$ and Joe B. Calkins Jr., ${ }^{2,3}$ \\ ${ }^{1}$ Internal Medicine Department, Georgia Health Sciences University, Augusta, GA 30912, USA \\ ${ }^{2}$ Cardiology Department, Georgia Health Sciences University, Augusta, GA 30912, USA \\ ${ }^{3}$ Cardiology Department, Charlie Norwood VA Medical Center, Augusta, GA 30904, USA \\ Correspondence should be addressed to Jonathan D. Gardner, jongardner@georgiahealth.edu
}

Received 2 October 2012; Accepted 18 October 2012

Academic Editors: G. Devlin and T. Kasai

Copyright ( 92012 Jonathan D. Gardner et al. This is an open access article distributed under the Creative Commons Attribution License, which permits unrestricted use, distribution, and reproduction in any medium, provided the original work is properly cited.

\begin{abstract}
The case of a patient who presented with angina following a coronary artery bypass (CABG) operation during which the left internal mammary artery was inadvertently anastomosed to a cardiac vein is presented. The literature concerning previously reported cases of aortocoronary arteriovenous fistulas (ACAVF) due to inadvertent grafting of a coronary vein is reviewed and the significance of this complication is discussed. ACAVF due to inadvertent grafting of a coronary vein is a rare complication of $\mathrm{CABG}$ and may be a more common cause of graft failure than has previously been recognized. Distortion of cardiac anatomy, the presence of epicardial fat, and an intramyocardial course of the artery intended for grafting are predisposing factors. Some patients present with angina pectoris and heart failure whereas others have no symptoms. The diagnostic test of choice is coronary angiography. Cardiac MRI and CT have a limited role due to the smaller size and the more clearly defined course of these fistulas. Asymptomatic patients are simply observed since spontaneous closure of these fistulas is reported. Symptomatic patients can be treated with combined medical management and percutaneous methods.
\end{abstract}

\section{Introduction}

Iatrogenic aortocoronary arteriovenous fistula (ACAVF) resulting from placement of an arterial graft to a cardiac vein is a rare complication of CABG. We present a case involving grafting of the left internal mammary artery (LIMA) to a left coronary vein and a review of the literature.

\section{Patient Presentation}

The patient is a 69-year-old male with hypertension, hyperlipidemia, and type 2 diabetes mellitus who presented with exertional chest pain, dyspnea, decreased functional capacity and occasional palpitations. A myocardial perfusion study one month earlier had demonstrated inferolateral ischemia and preserved left ventricular systolic function (EF 69\%).

Subsequent left heart catheterization (LHC) showed $70 \%$ ostial left main stenosis (Figure 1), 60\% left anterior descending artery (LAD) stenosis, and complete occlusion of the mid circumflex artery with filling via right to left collaterals. The right coronary artery (RCA) had 70\% stenosis in its midportion and left ventricular systolic function was normal. He underwent CABG with the following grafts: LIMA to the LAD, SVG to OM, and SVG to the PDA. Postoperative course was uncomplicated.

Three months later, the patient presented with exertional chest pain similar to his pain prior to surgery. Repeated LHC showed no change in the native coronary arteries and patent SVG to OM and SVG to PDA with good flow. Angiography of the LIMA demonstrated that it was anastomosed to a cardiac vein with resultant flow into the coronary sinus (Figure 2).

Percutaneous coronary intervention (PCI) was performed with placement of three drug eluting stents in the LM and ostial/proximal LAD. There was no residual stenosis (Figure 3). Subsequently, eight $3 \mathrm{~mm}$ stainless steel coils were deployed in the distal portion of the LIMA just proximal to 


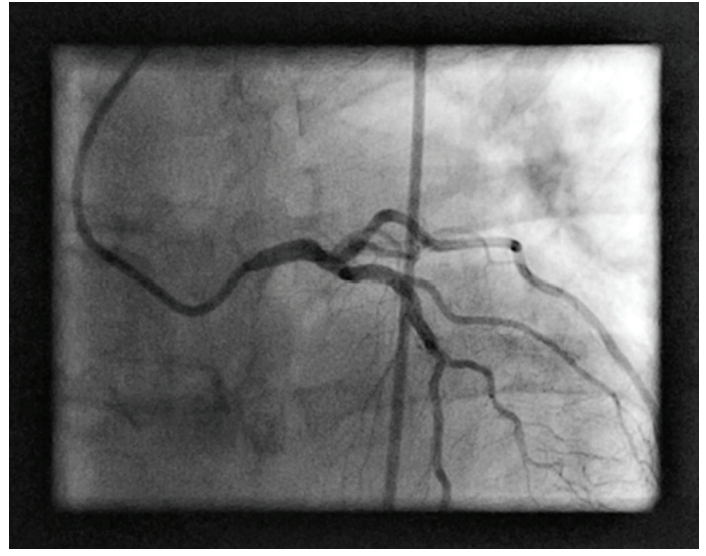

Figure 1: Left anterior oblique view of the left coronary artery. A JL4 catheter is seen engaging the left coronary artery. The ostial left main is tapered and has a $70 \%$ stenosis.

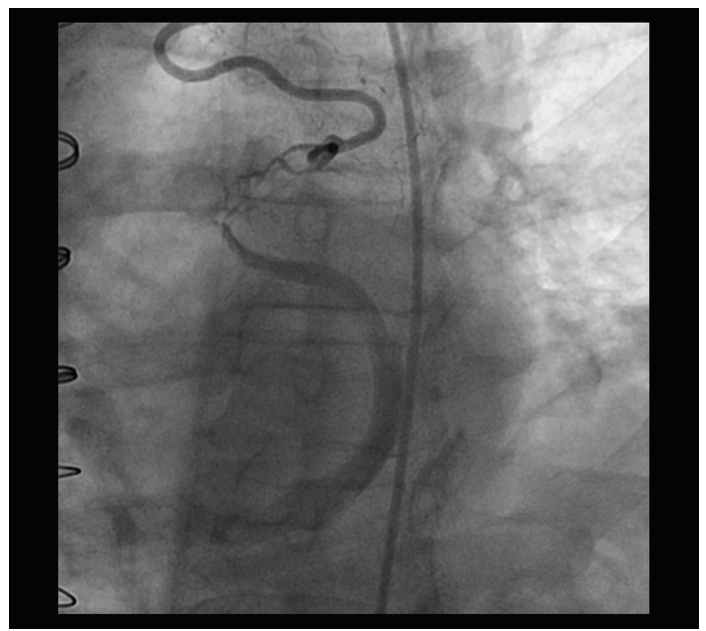

FIgURe 2: This is an angiogram of the left internal mammary artery as it anastomoses to a cardiac vein. Contrast fills the coronary sinus as it traverses the posterior atrioventricular groove.

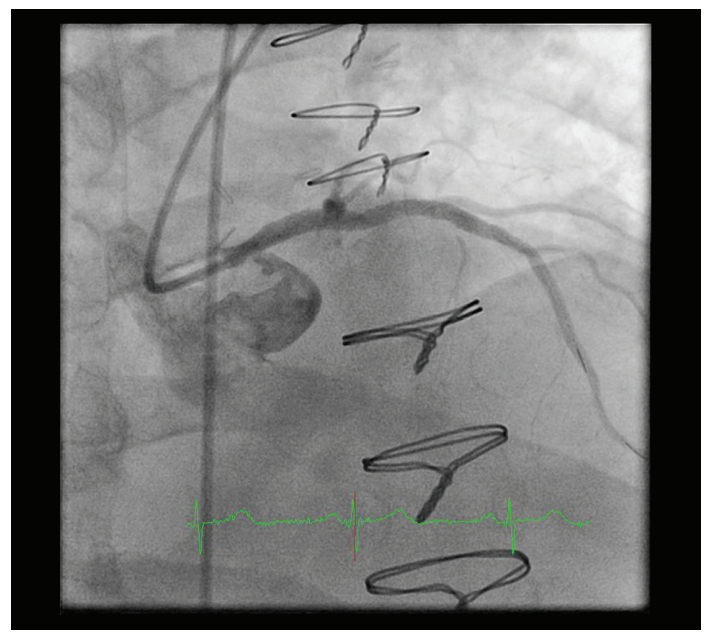

FIGURE 3: Right anterior oblique view of the left coronary artery following left main and LAD intervention. The left main is no longer tapered and the contrast effluxes out of the left main into the left coronary cusp of the aortic valve.

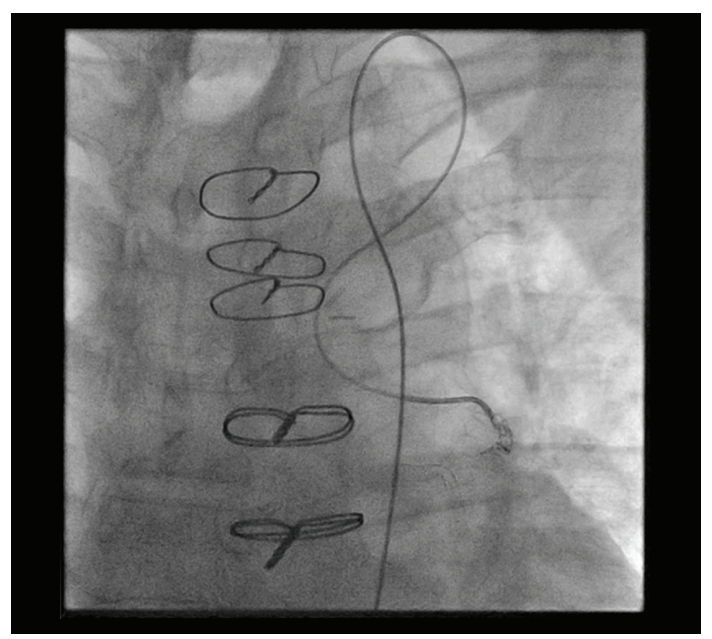

FIgure 4: Angiogram of the deployment of the coils in the distal left internal mammary artery. The catheter is accessing the LIMA via the left subclavian artery.

the anastomosis with the cardiac vein with resultant occlusion of the LIMA (Figure 4).

Six months after the intervention, the patient had a repeated myocardial perfusion study. No ischemia was demonstrated and LV systolic function was normal. He has remained asymptomatic.

\section{Discussion}

Iatrogenic ACAVF resulting from inadvertent grafting to a coronary vein is a rare complication of CABG. Only 36 cases have been reported (Table 1). Deligonul et al. [24] reported two cases of ACAVF, which closed spontaneously, suggesting that this complication may be more frequent than previously thought. Symptomatic patients experiencing spontaneous closure of the ACAVF would be found to have an occluded graft and an unbypassed artery with coronary angiography. It may be unrecognized in other patients with this complication since they may remain asymptomatic or significantly less symptomatic following bypass surgery and would have no indication for coronary angiography.

This complication can result in significant morbidity by several mechanisms. Postoperative angina can occur either as a result of either residual ischemia due to an unbypassed artery or a coronary steal phenomenon. A state of high output failure can result if there is a significant degree of left-to-right shunting over an extended period of time. If left untreated, shunting can cause other complications, such as bacterial endocarditis or fistula rupture $[15,17,19,28,29]$. Although significant morbidity may arise, some patients remain asymptomatic and spontaneous closure of the fistula can occur [24].

As this is a rare complication, predisposing factors are difficult to identify. It is reasonable to assume that anatomical distortion of the myocardium may increase the risk of iatrogenic anastomosis of a graft to a cardiac vein. The presence of scarring and fibrosis following pericardial disease, 


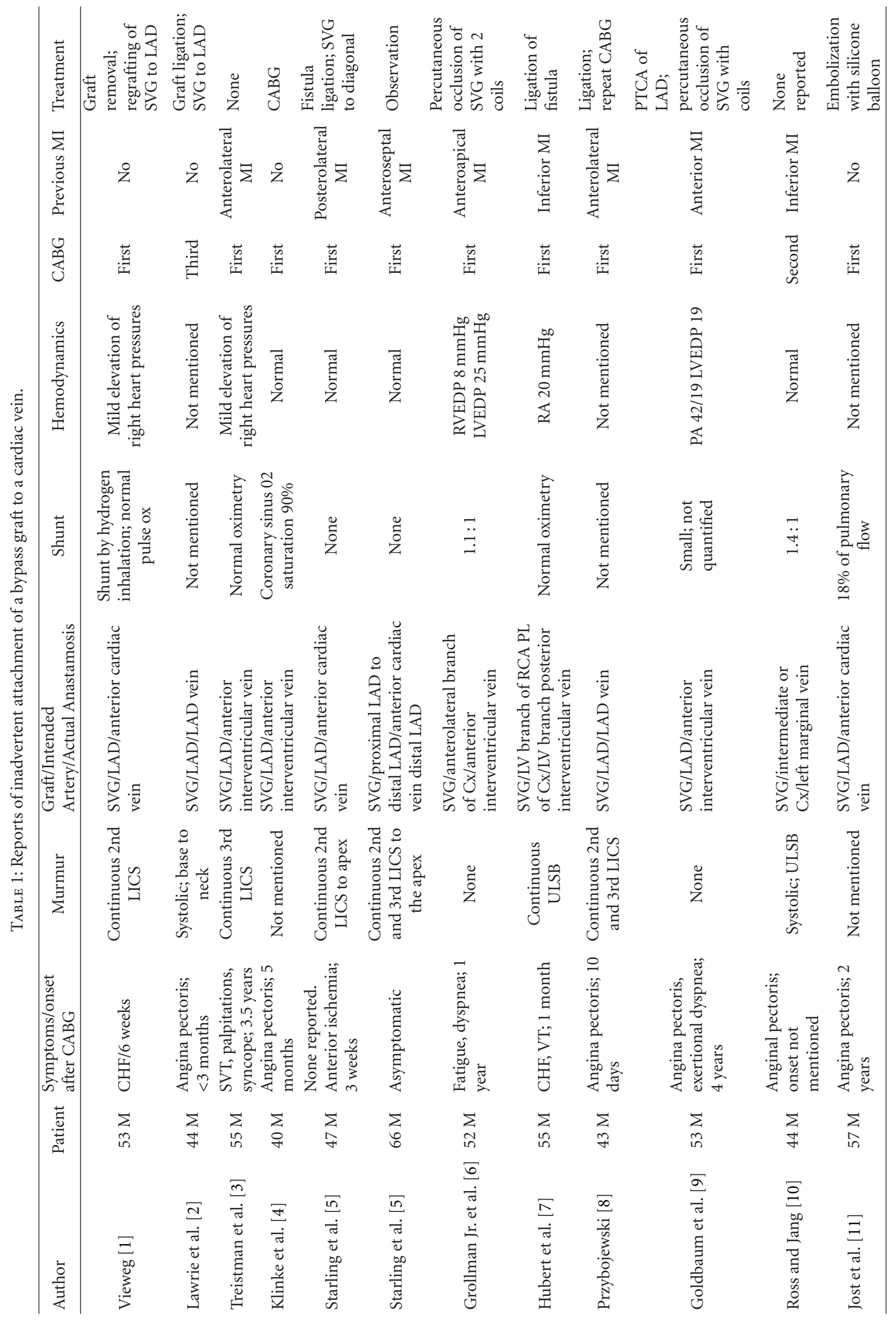




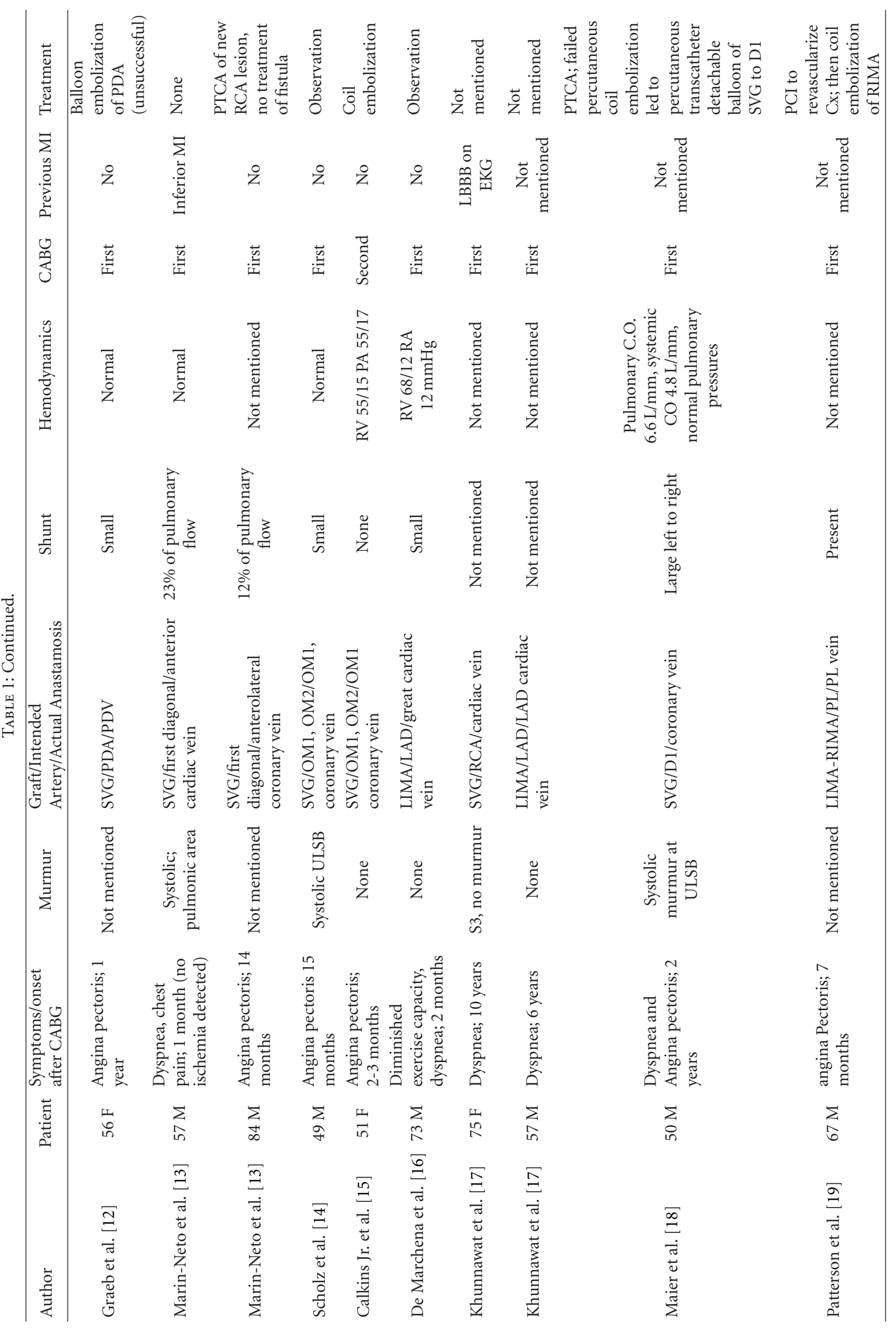




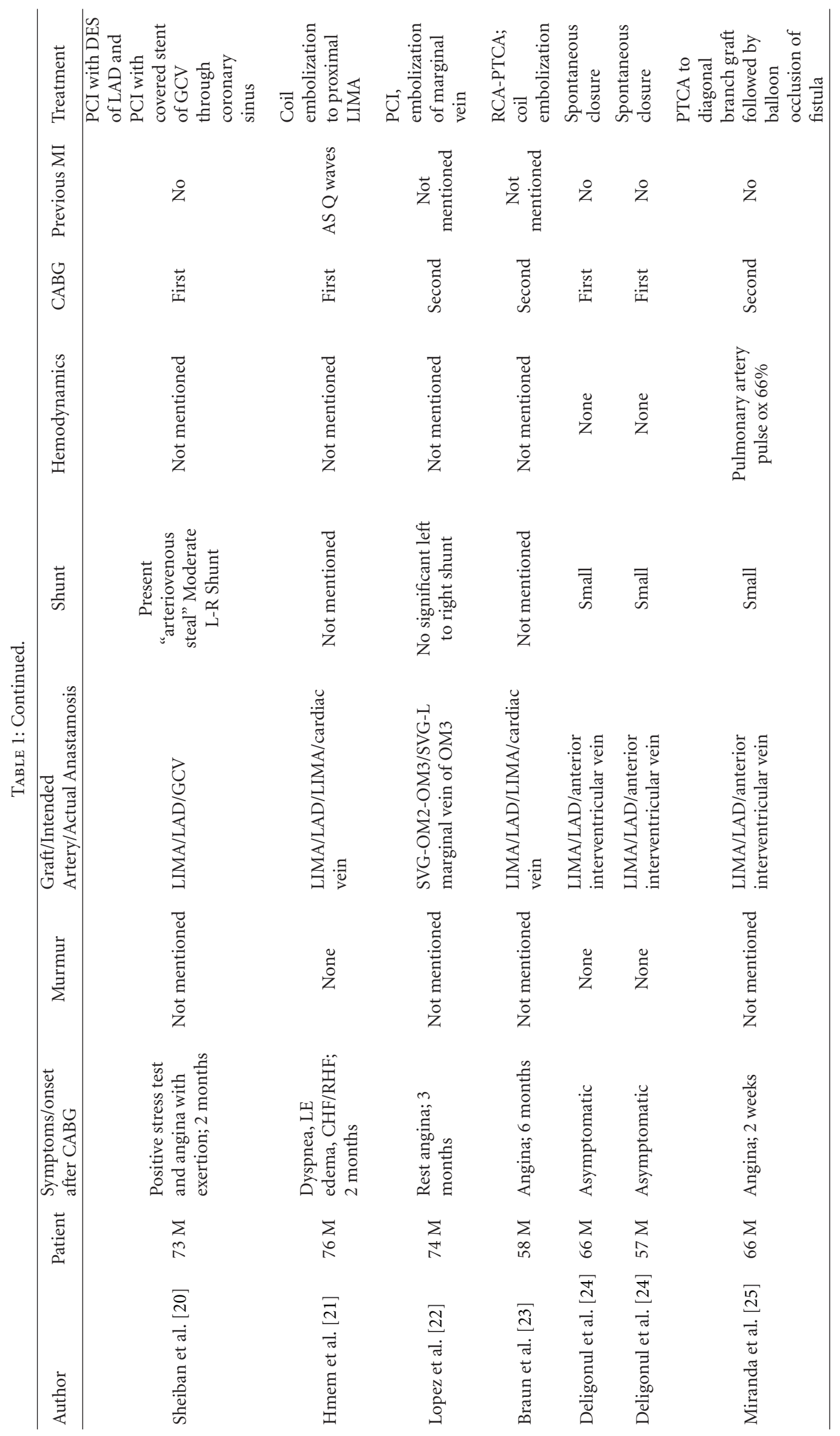




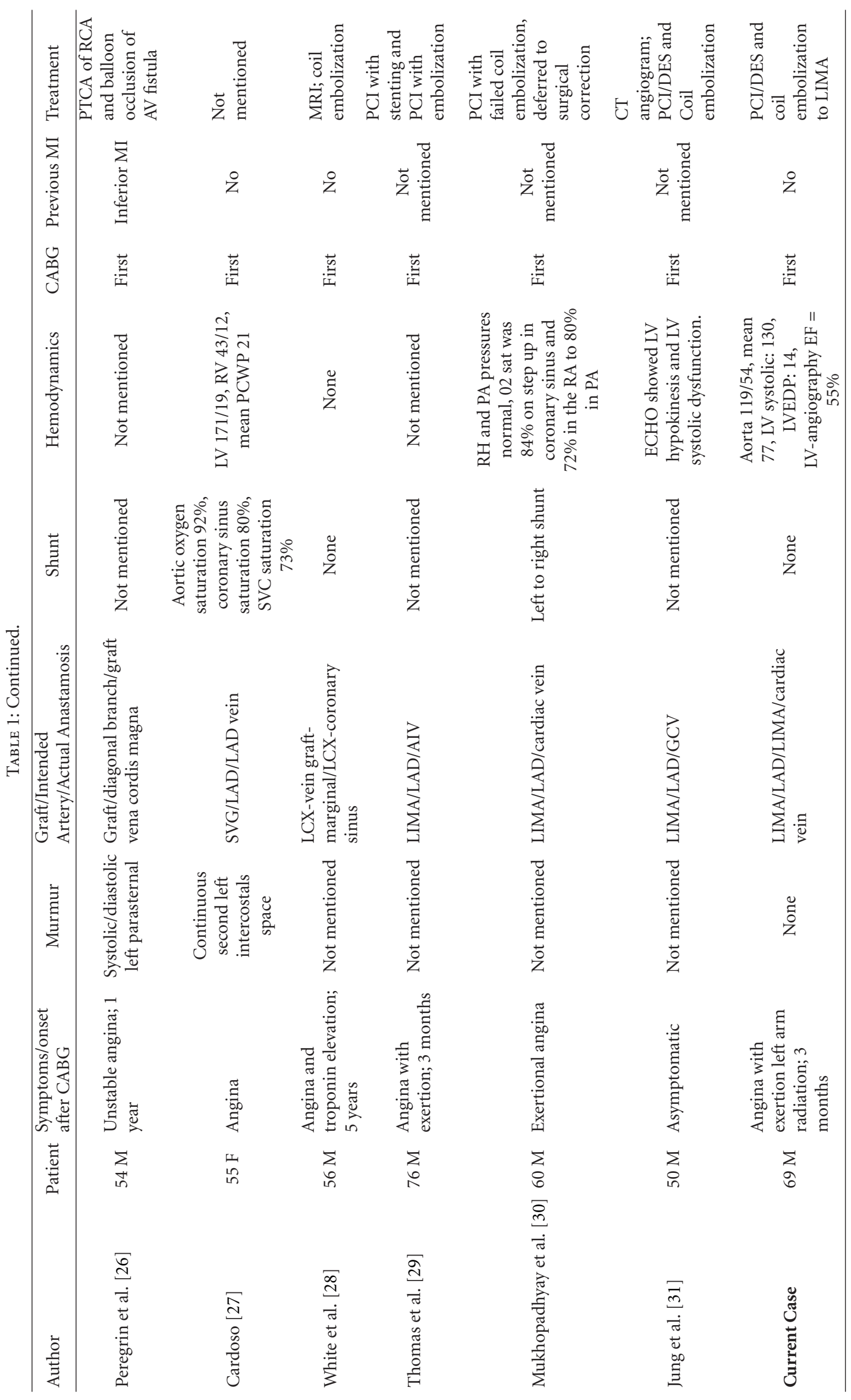


myocardial infarction (MI), or previous CABG as well as the presence of epicardial fat can make identification of the artery more difficult $[15,19,20,29]$. Thirty-five percent of patients had a previous MI and $18 \%$ had undergone CABG. The majority of cases involved the LAD (22 patients, $61 \%$ ) and its diagonal branch (4 patients, 11\%), which can be deeply embedded in epicardial fat or myocardium.

The majority of patients presented with angina (23 patients, $63.9 \%$ ) or dyspnea (8 patients, $22.2 \%$ ) (Table 1 ). Three presented with heart failure symptoms, two with arrhythmias (VT and SVT), one with syncope, and one with diminished exercise capacity. Four were asymptomatic. No symptoms were reported for another patient who was found to have anterior ischemia on an ECG. The time of onset of symptoms following CABG was variable, ranging from 10 days [8] to 10 years [17]. No obvious trend was present concerning the onset of symptoms following CABG. Symptoms occurred in 14 patients within the first three months postoperatively and between one and 10 years postoperatively in 16 patients.

The most common physical finding was a continuous or systolic murmur, followed by signs of heart failure (Table 1). However, the majority of reports did not mention whether or not a murmur was present.

In all of the reported cases, the standard diagnostic tool was LHC since it allows direct visualization of the ACAVF and guides percutaneous therapy. Right heart catheterization (RHC) was performed in 19 cases and demonstrated elevated filling pressures in nine patients and normal pressures in 10 (Table 1).

Coronary angiography can identify the origin of a coronary fistula and assess hemodynamics, but may fail to demonstrate the relation to other structures and the drainage site [32]. Cardiac MRI and CT angiography have emerged as valuable modalities to demonstrate the size, course, anatomic connection, and other anatomic features of larger and more complex congenital and acquired coronary fistulas [32, 33] and provide valuable information necessary for surgical treatment [34-38]. None of the more recently reported ACAVFs due to inadvertent grafting of a coronary vein were evaluated by MRI or CT, most likely because these fistulas are smaller and better defined and because surgical closure has been replaced by percutaneous treatments.

Medical management and observation remain the treatment of choice for asymptomatic patients. Deligonul et al. [24] presented 2 cases of asymptomatic iatrogenic ACAVF, which closed spontaneously while the patients received medical management, supporting a more conservative approach to these patients. For symptomatic patients and those who are refractory to medical therapy, surgical closure of the ACAVF and grafting of the native artery have historically been preferred. With improvements in percutaneous methods, coil or balloon embolization, sometimes combined with stenting of the ungrafted artery, have become the new standard $[18,29]$. In nearly half of the reported patients who were treated percutaneously ( 7 out of 15 ), the unbypassed vessel was not treated and the patient was treated with optimal medical therapy for coronary artery disease. These patients remained asymptomatic, suggesting that the shunt, rather than the unbypassed artery, might have been the underlying cause of the patients' symptoms.

Another advance in the treatment of this complication is the percutaneous approach to the ACAVF via the coronary sinus. Sheiban et al. [20] described a case in which a covered stent was deployed in the cardiac vein using this approach for the closure of an end-to-side anastomosis of the graft to the vein. Additionally, Lopez et al. [22] also used a coronary sinus approach to treat a side-to-side anastomosis of the proximal segment of a sequential graft that was anastomosed to a cardiac vein, with preservation of the distal end-to-side anastomosis to the coronary artery.

\section{Conclusion}

Iatrogenic aorto-coronary arteriovenous fistula due to inadvertent anastomosis of a bypass graft to a cardiac vein is a rare complication that is probably more common than previously believed and may be a more frequent cause of graft failure and recurrent angina following CABG. Anatomical distortion of the surface of the myocardium, the presence of epicardial fat, and an intramyocardial course of the intended artery for grafting are predisposing factors.

Left heart catheterization is the diagnostic test of choice for this complication. Cardiac MRI and CTA have a more limited diagnostic role due to the smaller size of the fistula and its more easily defined course when compared to congenital and other types of acquired coronary artery fistulas. Asymptomatic patients should be observed and managed medically as they may have spontaneous closure of their fistulas. Percutaneous embolization with either detachable balloons or coils combined with stenting of the ungrafted artery is an effective and safe method of treatment for symptomatic patients.

\section{Conflict of Interests}

There is no conflict of interests among any of the authors of this paper.

\section{References}

[1] W. V. R. Vieweg, "Continuous murmur following bypass surgery," Chest, vol. 79, no. 1, pp. 4-5, 1981.

[2] G. M. Lawrie, G. C. Morris Jr., and W. L. Winters, "Aortocoronary saphenous vein autograft accidentally attached to a coronary vein: follow up angiography and surgical correction of the resultant arteriovenous fistula," Annals of Thoracic Surgery, vol. 22, no. 1, pp. 87-90, 1976.

[3] B. Treistman, T. A. Sulbaran, and D. A. Cooley, "Saphenous vein bypass from the aorta to the anterior interventricular vein," Annals of Thoracic Surgery, vol. 26, no. 4, pp. 383-386, 1978.

[4] W. P. Klinke, C. J. Pepine, and C. R. Conti, "Demonstration of inadvertently created aorto-coronary venous anastomosis: evidence against the clinical effectiveness of retrograde coronary venous perfusion," Catheterization and Cardiovascular Diagnosis, vol. 5, no. 4, pp. 367-370, 1979.

[5] M. R. Starling, B. M. Groves, and D. Frost, "Aorto-coronary vein fistula. A complication of coronary artery bypass graft surgery," Chest, vol. 79, no. 1, pp. 64-68, 1981. 
[6] J. H. Grollman Jr., H. G. Lund, and J. V. Redington, "Percutaneous embolic occlusion of an inadvertent surgical aortocoronary vein fistula," Catheterization and Cardiovascular Diagnosis, vol. 8, no. 3, pp. 287-292, 1982.

[7] J. W. Hubert, S. Thanavaro, R. Ruffy, J. Connors, and G. C. Oliver, "Saphenous vein bypass to the posterior interventricular vein: an unusual complication of coronary artery surgery," Southern Medical Journal, vol. 75, no. 9, pp. 1144-1146, 1982.

[8] J. Z. Przybojewski, "Iatrogenic aortocoronary vein fistula. A case presentation and review of the literature," South African Medical Journal, vol. 62, no. 24, pp. 908-917, 1982.

[9] T. S. Goldbaum, H. B. Marsh, and D. D. Maxwell, "Simultaneous percutaneous transluminal coronary angioplasty and transcatheter embolization of latrogenic aortocoronary vein fistula," American Journal of Cardiology, vol. 55, no. 5, pp. 578580, 1985.

[10] P. J. Ross and G. C. Jang, "Iatrogenic fistula from the aorta to the left marginal coronary vein," Chest, vol. 87, no. 3, pp. 398399, 1985.

[11] S. Jost, R. Simon, I. Amende, G. H. Reil, G. Herrmann, and P. R. Lichtlen, "Therapeutic occlusion of an inadvertently implanted ACVB graft by transluminal balloon embolization," Zeitschrift für Kardiologie, vol. 77, no. 11, pp. 746-748, 1988.

[12] D. A. Graeb, D. C. Morris, D. R. Ricci, and G. F. Tyers, "Balloon embolization of latrogenic aortocoronary arteriovenous fistula," Catheterization and Cardiovascular Diagnosis, vol. 20, no. 1, pp. 58-62, 1990.

[13] J. A. Marin-Neto, M. V. Simoes, and W. V. A. Vicente, "Acquired aorto-coronary vein fistula after bypass graft surgery: report of two cases with long-term follow-up," International Journal of Cardiology, vol. 30, no. 1, pp. 121-124, 1991.

[14] K. H. Scholz, V. Wiegand, P. Rosemeyer, J. M. Chemnitius, and H. Kreuzer, "Aorto-coronary artery to coronary vein fistula with the potential of coronary steal as complication of saphenous vein jump bypass graft," European Journal of Cardio-Thoracic Surgery, vol. 7, no. 8, pp. 441-442, 1993.

[15] J. B. Calkins Jr., J. D. Talley, and N. H. Kim, "Iatrogenic aortocoronary venous fistula as a complication of coronary artery bypass surgery: patient report and review of the literature," Catheterization and Cardiovascular Diagnosis, vol. 37, no. 1, pp. 55-59, 1996.

[16] E. De Marchena, B. Musial, P. Wozniak, A. Schob, S. Chakko, and K. M. Kessler, "Iatrogenic internal mammary artery to coronary vein fistula," Chest, vol. 97, no. 1, pp. 251-252, 1990.

[17] C. Khunnawat, S. Mukerji, G. S. Abela, and R. K. Thakur, "Unusual complications of coronary artery bypass graft surgery," American Journal of Cardiology, vol. 98, no. 12, pp. 16651666, 2006.

[18] L. S. Maier, A. B. Buchwald, B. Ehlers, K. Rühmkorf, and K. H. Scholz, "Closure of an latrogenic aortocoronary arteriovenous fistula: transcatheter balloon embolization following failed coil embolization and salvage of coils that migrated into the coronary venous system," Catheterization and Cardiovascular Interventions, vol. 55, no. 1, pp. 109-112, 2002.

[19] M. S. Patterson, S. Vaina, and P. W. Serruys, "Percutaneous treatment of an iatrogenic cardiac fistula," Catheterization and Cardiovascular Interventions, vol. 72, no. 2, pp. 259-262, 2008.

[20] I. Sheiban, C. Moretti, and S. Colangelo, "Iatrogenic left internal mammary artery-coronary vein anastomosis treated with covered stent deployment via retrograde percutaneous coronary sinus approach," Catheterization and Cardiovascular Interventions, vol. 68, no. 5, pp. 704-707, 2006.
[21] M. Hmem, M. Elbaz, T. Filali et al., "Percutaneous embolisation of a iatrogenic fistula between the internal mammary artery and the coronary vein," Archives des Maladies du Coeur et des Vaisseaux, vol. 98, no. 10, pp. 1022-1025, 2005.

[22] J. J. Lopez, R. E. Kuntz, D. S. Baim, R. G. Johnson, and D. Kim, "Percutaneous occlusion of an iatrogenic aortosaphenous vein-coronary vein fistula via retrograde coronary sinus approach," Catheterization and Cardiovascular Diagnosis, vol. 37, no. 3, pp. 339-341, 1996.

[23] P. Braun, R. Höltgen, E. Stroh et al., "Coil embolization of an AV-fistula between the left thoracic artery and vein after coronary artery bypass surgery," Zeitschrift für Kardiologie, vol. 88, no. 10, pp. 812-814, 1999.

[24] U. Deligonul, M. Vandormael, J. M. Harper, and M. J. Kern, "Spontaneous closure of iatrogenic left internal mammary artery to anterior interventricular vein fistula," American Journal of Cardiology, vol. 58, no. 9, pp. 854-855, 1986.

[25] A. A. Miranda, J. A. Hill, J. P. Mickle, and R. G. Quisling, "Balloon occlusion of an internal mammary artery to anterior interventricular vein fistula," American Journal of Cardiology, vol. 65, no. 3, pp. 257-258, 1990.

[26] J. H. Peregrin, M. Zelizko, and J. Kovac, "Detachable balloon embolization of an iatrogenic aortocoronary arteriovenous fistula combined with aortocoronary bypass PTCA: a case report," Catheterization and Cardiovascular Diagnosis, vol. 27, no. 2, pp. 137-140, 1992.

[27] C. R. Cardoso, "Saphenous vein bypass from aorta to coronary vein accidentally performed: diagnostic aspects. Report of a case," Arquivos Brasileiros de Cardiologia, vol. 41, no. 6, pp. 455-457, 1983.

[28] R. W. White, M. U. Sivananthan, and P. H. Kay, "Aortocoronary bypass graft fistula after surgical treatment of circumflex coronary artery fistula: a unique variation of a rare condition successfully treated with percutaneous embolization," Interactive Cardiovascular and Thoracic Surgery, vol. 10, no. 2, pp. 256-257, 2010.

[29] W. J. Thomas, W. B. Moskowitz, A. Freedman, G. W. Vetrovec, and E. Goudreau, "Therapeutic embolization for unusual iatrogenic complications related to coronary revascularization," Catheterization and Cardiovascular Interventions, vol. 46, no. 4, pp. 457-462, 1999.

[30] S. Mukhopadhyay, J. Yusuf, M. D. Gupta, M. P. Girish, and V. Trehan, "Iatrogenic aortocoronary arteriovenous fistula," Indian Heart Journal, vol. 56, no. 6, pp. 680-681, 2004.

[31] I. S. Jung, J. O. Jeong, S. S. Kim et al., "Iatrogenic left internal mammary artery to great cardiac vein anastomosis treated with coil embolization," Korean Circulation Journal, vol. 41, no. 2, pp. 105-108, 2011.

[32] F. Gundogdu, S. Arslan, E. Buyukkaya, and M. Kantarci, "Coronary artery fistula in a patient with coronary artery disease: evaluation by coronary angiography and multidetector computed tomography," The International Journal of Cardiovascular Imaging, vol. 23, no. 2, pp. 299-302, 2007.

[33] H. J. Seon, Y. H. Kim, S. Choi, and K. H. Kim, "Complex coronary artery fistulas in adults: evaluation with multidetector computed tomography," The International Journal of Cardiovascular Imaging, vol. 26, no. 2, pp. 261-271, 2010.

[34] J. D. Schilling and J. J. Billadello, "Right coronary artery to coronary sinus fistula by transesophageal echocardiogram, cardiac magnetic resonance imaging, and coronary angiography," Clinical Cardiology, vol. 32, no. 7, pp. E29-E30, 2009.

[35] A. Weymann, A. Lembcke, and W. F. Konertz, "Right coronary artery to superior vena cava fistula: imaging with cardiac 
catheterization, 320-detector row computed tomography, magnetic resonance imaging, and transoesophageal echocardiography," European Heart Journal, vol. 30, no. 17, article 2146, 2009.

[36] A. Maleszka, G. Kleikamp, K. Minami, A. Peterschröder, and R. Körfer, "Giant coronary arteriovenous fistula: a case report and review of the literature," Zeitschrift für Kardiologie, vol. 94, no. 1, pp. 38-43, 2005.

[37] U. Aydoğan, E. Onursal, T. Cantez, C. Barlas, B. Tanman, and L. Gürgan, "Giant congenital coronary artery fistula to left superior vena cava and right atrium with compression of left pulmonary vein simulating cor triatriatum-diagnostic value of magnetic resonance imaging," European Journal of CardioThoracic Surgery, vol. 8, no. 2, pp. 97-99, 1994.

[38] L. Gruberg, L. F. Satler, A. J. Pfister, L. H. Monsein, and M. B. Leon, "A large coronary artery saphenous vein bypass graft aneurysm with a fistula: case report and review of the literature," Catheterization and Cardiovascular Interventions, vol. 48, no. 2, pp. 214-216, 1999. 


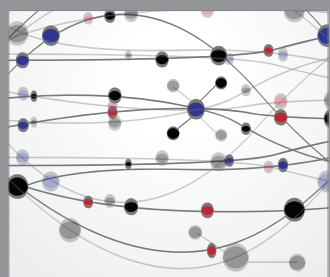

The Scientific World Journal
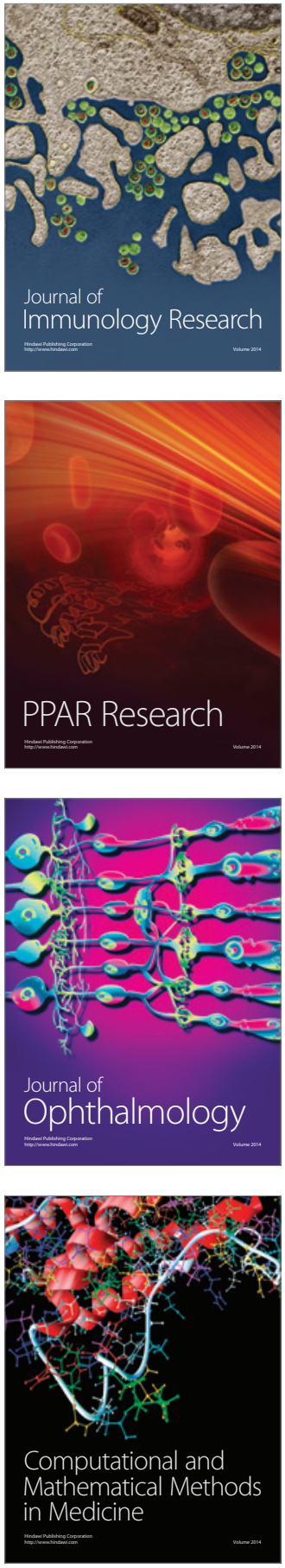

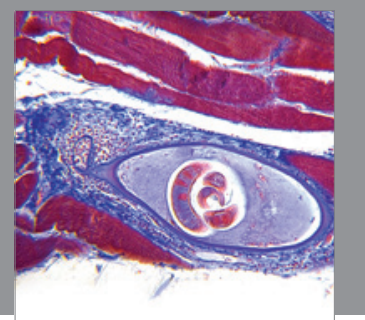

Gastroenterology

Research and Practice
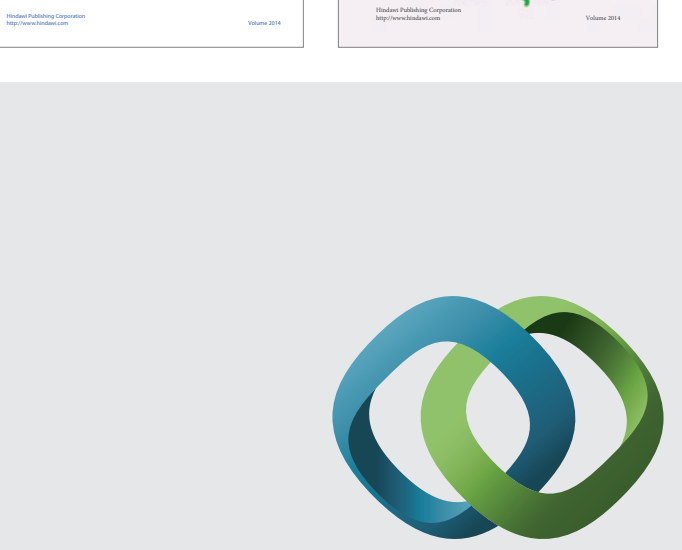

\section{Hindawi}

Submit your manuscripts at

http://www.hindawi.com
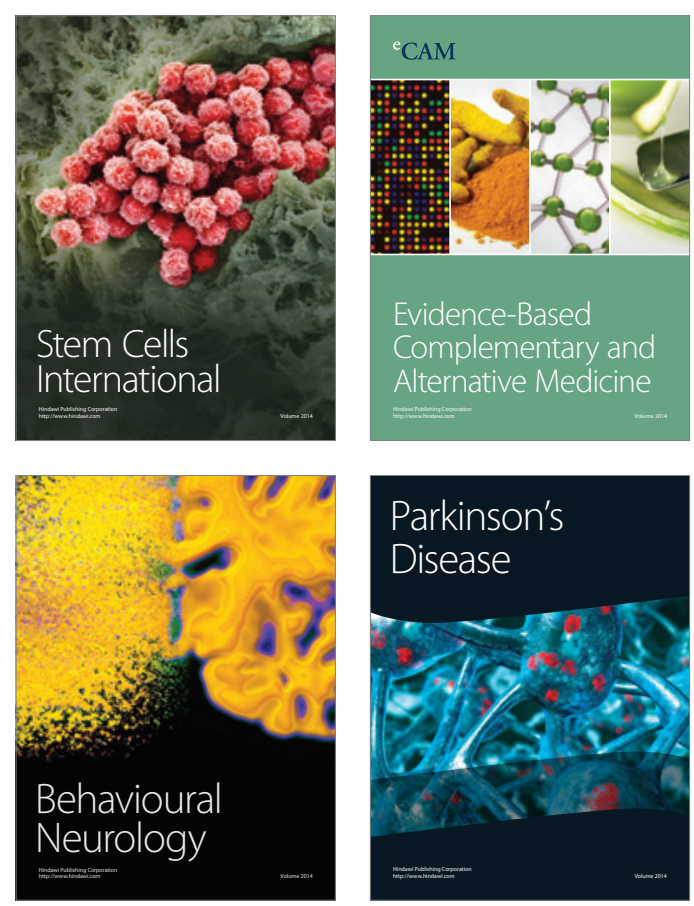

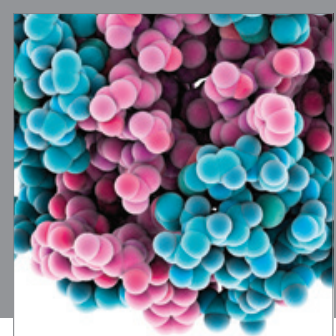

Journal of
Diabetes Research

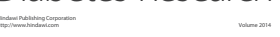

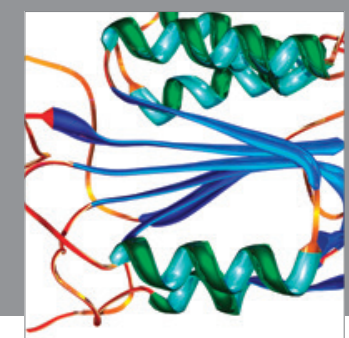

Disease Markers
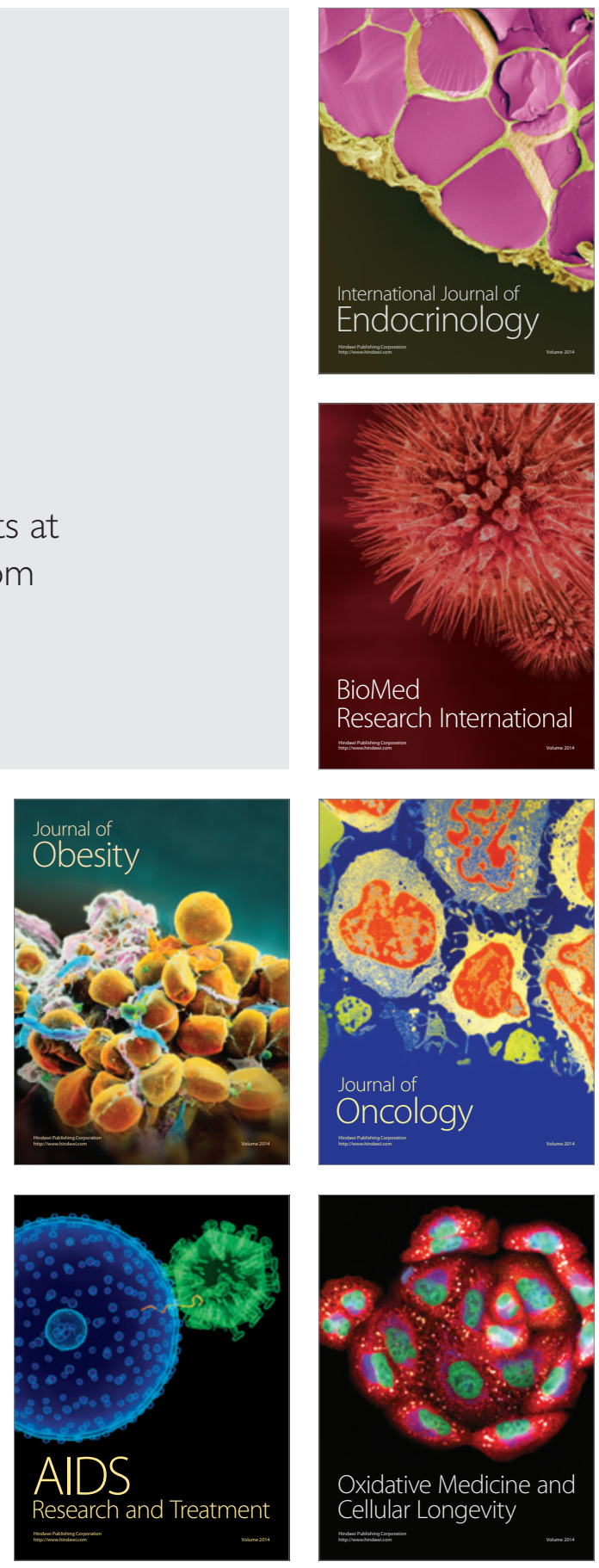